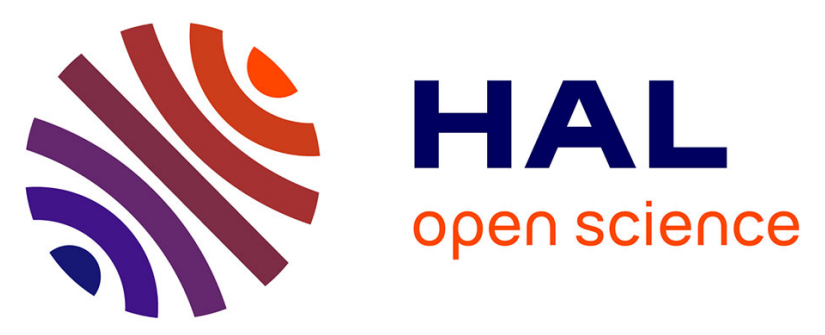

\title{
Bayesian predictive model to assess BRCA2 mutational status according to clinical history: Early onset, metastatic phenotype or family history of breast/ovary cancer
}

Priscilla Leon, Geraldine Cancel-Tassin, Violaine Bourdon, Bruno Buecher, Stephane Oudard, Laurent Brureau, Lionel Jouffe, Pascal Blanchet, Dominique Stoppa-Lyonnet, Florence Coulet, et al.

\section{- To cite this version:}

Priscilla Leon, Geraldine Cancel-Tassin, Violaine Bourdon, Bruno Buecher, Stephane Oudard, et al.. Bayesian predictive model to assess BRCA2 mutational status according to clinical history: Early onset, metastatic phenotype or family history of breast/ovary cancer. Prostate, 2021, 81 (6), pp.318325. 10.1002/pros.24109 . hal-03153082

\section{HAL Id: hal-03153082 https://hal.sorbonne-universite.fr/hal-03153082}

Submitted on 26 Feb 2021

HAL is a multi-disciplinary open access archive for the deposit and dissemination of scientific research documents, whether they are published or not. The documents may come from teaching and research institutions in France or abroad, or from public or private research centers.
L'archive ouverte pluridisciplinaire HAL, est destinée au dépôt et à la diffusion de documents scientifiques de niveau recherche, publiés ou non, émanant des établissements d'enseignement et de recherche français ou étrangers, des laboratoires publics ou privés. 
Bayesian predictive model to assess BRCA2 mutational status according to clinical history: early onset, metastatic phenotype or family history of breast/ovary cancer

Priscilla Leon $\mathrm{MD}^{1,2}$, Geraldine Cancel Tassin $\mathrm{PhD}^{2,3}$, Violaine Bourdon $\mathrm{PhD}^{4}$, Bruno Buecher MD, $\mathrm{PhD}^{5}$, Stephane Oudard MD, $\mathrm{PhD}^{6}$, Laurent Brureau MD, $\mathrm{PhD}^{7,8}$, Lionel Jouffe $\mathrm{PhD}^{9}$, Pascal Blanchet $\mathrm{MD}$, $\mathrm{PhD}^{7,8}$, Dominique Stoppa-Lyonnet $\mathrm{MD}, \mathrm{PhD}^{5}$, Florence Coulet $\mathrm{MD}, \mathrm{PhD}^{10}$, Hagay Sobol MD, $\mathrm{PhD}^{4}$, Olivier Cussenot MD, $\mathrm{PhD}^{2,3}$.

1. Department of Urology, Clinique Pasteur, Royan, France

2. Sorbonne Université, GRC $n^{\circ} 5$ Predictive Onco-Urology, AP-HP, Hopital Tenon, Paris, France

3. CeRePP, Paris, France

4. Department of Prevention and Screening Genetic Oncology, Institut Paoli-Calmettes, Marseille, France

5. Department of Genetics, Institut Curie, Paris, France

6. Department of Oncology Unit, Hôpital Européen Georges Pompidou, APHP, Paris, France

7. Department of Urology, CHU Pointe-à-Pitre/Abymes, Pointe à Pitre, Guadeloupe

8. Inserm, EHESP, Irset (Institut de recherche en santé, environnement et travail) - UMR_S 1085, Pointe-à-Pitre, Guadeloupe

9. Bayesia SAS, Changé, France

10. Department of Genetics, Oncogenetics Consulting, Oncogenetics Functional Unit, Groupe Hospitalier Pitié-Salpêtrière APHP, Paris, France 
Corresponding author:

Geraldine Cancel-Tassin, PhD

CeRePP/ GRC n5, Hopital Tenon, 4 rue de la Chine, 75020 PARIS

Phone: +33156017646 ; Fax : +33156017647

Email: g.cancel@cerepp.org

Shortened title: Bayesian model to assess BRCA2 status

Keywords: Prostate cancer; BRCA2; DNA damage and repair; mutation; survival.

\section{ADDITIONNAL INFORMATION}

Data availability statement The datasets used and/or analysed during the current study are available from the corresponding author on reasonable request.

Funding statement This work was supported by grant from the French National Cancer Institute (INCa) [grant number: 2017-016] and from the Fonds de Dotation pour l'Innovation dans la prise en charge du Cancer de Prostate (FDCP).

Conflict of interest disclosure The authors declare no competing interests.

Ethics approval statement The PROGENE study was approved by the CCP lle de France IV (IRB:

00003835). The study was performed in accordance with the Declaration of Helsinki.

Patient consent statement All patients selected for this study were recruited in the PROGENE study (FWA00006032), and provided written informed consent in order to participate in the study. This paper does not contain any individual person's data in any form. 
Permission to reproduce material from other sources Not applicable

Clinical trial registration Not applicable 


\section{ABSTRACT:}

Background: Mutations of the $B R C A 2$ gene are the most frequent alterations found in germline DNA from men with prostate cancer ( $\mathrm{PrCa}$ ), but clinical parameters that could better orientate for $B R C A 2$ mutation screening need to be established.

Methods: Germline DNA from 325 PrCa patients (median age at diagnosis: 57 years old) was screened for BRCA2 mutation. The mutation frequency was compared between three subgroups: patients with an age at diagnosis at 55 years old and under (Group I); a personal or family history of breast, uterine or ovarian cancer (Group II); or a metastatic disease (Group III). Frequency of BRCA2 mutations was established for each combination of phenotypes, and compared between patients meeting or not the criteria for each subgroup using Fisher's exact test. Mutual information, direct effect, elasticity and contribution to the mutational status of each phenotype, taking into account overlap between subgroups, were also estimated using Bayesian algorithms.

Results: The proportion of BRCA2 mutation was 5.9\% in Group I, $10.9 \%$ in Group II and $6.9 \%$ in Group III. The frequency of $B R C A 2$ mutation was significantly higher among patients of Group II ( $P=0.006)$, and reached $15.6 \%$ among patients of this group who presented a metastatic disease. Mutual information, direct effect, elasticity and contribution to the mutational status were the highest for phenotype II. Fifteen (71.4\%) of the 21 BRCA2 mutation carriers had an aggressive form of the disease. Four (19\%) of them died from PrCa after a median follow-up duration of 64.5 months.

Conclusions: Our results showed that a higher frequency of $B R C A 2$ mutation carriers is observed, not only among PrCa patients with young onset or a metastatic disease, but also with a personal or a familial history of breast cancer. 


\section{INTRODUCTION}

$B R C A 2$ is a tumor suppressor gene which plays an important role in the repair of double-strand DNA breaks by homologous recombination, and is mutated in early onset breast cancer $(\mathrm{BrCa})$ families. ${ }^{1}$ About $69 \%$ of women with a BRCA2 mutation will develop $\mathrm{BrCa}$ by the age of 80 , and $17 \%$ will develop an ovarian cancer (OvCa). ${ }^{2}$ BRCA2 mutation carriers also show an increased risk of prostate cancer $(\operatorname{PrCa})(\mathrm{RR}=4.65 ; 95 \% \mathrm{Cl}=3.48-6.22)^{3}$

Following report of clustering of $\mathrm{BrCa}$ and $\mathrm{PrCa}$ in BRCA2 positive families, Gayther et al. ${ }^{4}$ screened this gene in 38 patients with a family history of $\mathrm{PrCa}$, and found that these mutations accounted for about $5 \%$ of them. On their side, Edwards et al. reported that $2.3 \%$ of patients diagnosed before 56 years old who were unselected for family history had a germline BRCA2 mutation. ${ }^{5}$ In a larger study, the prevalence of $B R C A 2$ mutations was $1.2 \%$ in $\operatorname{PrCa}$ men with an age at onset $\leqslant 65$, and no mutation was observed in 243 patients with a family history of PrCa but diagnosed after 65 years old. ${ }^{6}$ More recently, germline DNA samples from 191 men with 3 or more PrCa cases in their family were sequenced for 22 genes involved in DNA-repair pathway and BRCA2 mutations were found as the most frequent event, accounting for $2.1 \%$ of the patients. ${ }^{7}$

BRCA2 mutations were also observed in $5.3 \%$ of 692 metastatic $\operatorname{PrCa}$ men, and were the most frequent ones (44\%) from the 20 analysed DNA-repair genes. ${ }^{8}$ The same percentage of germline BRCA2 mutation was observed in metastatic castration-resistant PrCa patients. ${ }^{9}$ Moreover, the metastatic patients who carry those mutations have been reported to exhibit attenuated or similar responses to standard hormonal therapy ${ }^{10}$ or taxanes ${ }^{11}$, but to respond better to next generation hormonal therapies ${ }^{12,13}$ and to inhibitors of the poly(adenosine diphosphate [ADP]- 
ribose) polymerases (PARPs). ${ }^{14}$ One of these PARP inhibitors, Lynparza ${ }^{\mathrm{TM}}$ (olaparib) has been granted breakthrough therapy designation by the U.S. Food and Drug Administration for monotherapy treatment of $B R C A 1 / B R C A 2$ or $A T M$ mutated metastatic castration-resistant PrCa patients who have received a prior taxane-based chemotherapy and at least one newer hormonal therapy.

Based on all these evidence, the latest National Comprehensive Cancer Network (NCCN) guidelines recommend the germline genetic screening of a panel of DNA-repair gene, including $B R C A 2$, in PrCa men that meet one of the following criteria: (1) High risk, very high risk, regional or metastatic PrCa regardless of family history, (2) a Ashkenazy Jewish origin, (3) a family history of high-risk germline mutation (eg BRCA1/2, Lynch mutation) and (4) a positive family history of cancer (consisting of a brother or father or multiple family members who were diagnosed with PrCa with an ISUP $>1$ at less than 60 years of age or who died from $\mathrm{PrCa}$, or $\geq 3$ cancers on the same side of family, especially diagnosed $\leq 50$ years of age: bile duct, breast, colorectal, endometrial, gastric, kidney, melanoma, ovarian, pancreatic, prostate with an ISUP $>1$, small bowel or urothelial cancer). ${ }^{15}$ However, Nicolosi et al. ${ }^{16}$ reported that $37 \%$ of PrCa patients who were found positive for a mutation of one of 13 DNA- repair genes or HOXB13 would not have been approved for genetic testing using these guidelines. Similarly, the Philadelphia Prostate Cancer Consensus Conference 2019 recommended germline testing of DNA-repair genes in case of metastatic PrCa or of family history suggestive of hereditary $\mathrm{PrCa}$, but in contrast, a moderate consensus was garnered for additional family history and pathologic criteria. ${ }^{17}$ In order to refine clinical parameters that could better orientate for $B R C A 2$ screening, we evaluated the frequency of $B R C A 2$ mutation among subgroups of a cohort of PrCa patients selected on three different phenotypes: (I) an early age at 
onset, (II) a personal or family history of breast (Br), uterine (Ut) or ovarian (Ov) cancer, and (III) a metastatic disease. Moreover, using a Bayesian predictive model that takes into account the potential interactions between data, we established the direct effect and the contribution to the mutation status of these three phenotypes.

\section{MATERIAL AND METHODS}

Study population

Patients of this study were participants of the PROGENE study, ${ }^{18}$ which has been approved by the CCP lle de France IV (IRB: 00003835), and have all provided written informed consent. They were selected based on one of the following three phenotypes: (I) diagnosed at 55 years old and under, (II) a personal history of $\mathrm{BrCa}$ and/or a first-degree relative with breast, uterine or ovarian cancer, or (III) metastatic PrCa. Family history of PrCa was considered as positive when the patient had a firstdegree relative with PrCa.

BRCA2 mutation screening

Germline DNA was extracted from blood or saliva using standardized protocols. For most of the patients, the full coding sequence and exon-intron junctions of the BRCA2 gene were screened for mutation (including for larger insertion or deletion), based on prescreening (DGGE, SSCP, PTA, dHPLC, HRM or EMMA) and sequencing. ${ }^{19}$ For the most recent samples, targeted next generation sequencing encompassing the full coding sequence of BRCA2 was performed. 


\section{Statistics}

Comparison of frequency of $B R C A 2$ mutations in patients meeting or not the criteria of each subgroup, according to family history of PrCa, or ethnicity was performed either using Fisher's exact test or Chi square test, using XLSTAT (Addinsoft, Paris, France). The predictive value of each phenotype was also analyzed using a Bayesian approach ${ }^{20}$. As the three clinical subgroups (I, II, and III) overlap, as often in real life where interactions between data are usual, we used a causal search algorithm. To understand how probability of mutational status was dependent on the variability of phenotype, mutual information, direct effect, elasticity and contribution to the mutational positive status were computed for each phenotype (I, II and III). These tools measure the responsiveness of one variable to changes in another, by analyzing both linear and non-linear dependencies, and provide a ranking of input variables based on their relative contributions to variability and mutual dependence (mutual information) of the evaluated results. It is typically used to rank the significant factors contributing to risk. Direct effects and elasticity are calculated from the percentage change in risk (y) divided by the percentage change in each input variable $(x)$ according to the formulas: Direct effect $=d y / d x$ and Elasticity $=[d y /(\operatorname{maxy}-\operatorname{miny})] /[d x /(\operatorname{maxx}-\min x)]$. Direct effect (measure of the effect of each variable on the target state, by controlling others) was estimated, using Minimum cross-entropy (MinxEnt) algorithm ${ }^{20}$, by slightly increasing the expected value of the driver while holding fixed the probability distributions of all other groups, and measuring the effect on the expected value of the mutational positive status. The analysis can be considered direct because all marginal probability distributions were held fixed, except those of all other groups. All Bayesian 
network analyses were performed with the Artificial Intelligence software BayesiaLab-9 (Bayesia SAS, Changé, France).

\section{RESULTS}

The characteristics of the 325 PrCa patients (median age at diagnosis: 57 years old) selected for this study are presented in Table 1. Among them, $152(46.8 \%)$ had an age at diagnosis at 55 years old and under (Group I), 137 (42.2\%) had a personal history of $\mathrm{BrCa}$ or a first degree with $\mathrm{BrCa}$, UtCa or OvCa (Group II), and 130 (40.0\%) were metastatic patients (Group III). Eighty-six patients (26.5\%) met at least two of the selection phenotypes: 38 (11.7\%) those of Groups I and II, $32(8.7 \%)$ those of Groups II and III, and lastly, 32 (8.7\%) those of Groups I and III. Eight (2.5\%) patient met all the three criteria. Among the 325 PrCa patients, a germline BRCA2 mutation was found in 21 (6.5\%). The observed proportion of BRCA2 mutations was 5.9\% (9/152) in Group I, 10.9\% (15/137) in Group II and 6.9\% (9/130) in Group III. The frequency of BRCA2 mutation carriers was significantly higher among the patients from Group II (P=0.006), and reached 15.6\% (5/32) among the ones who were also metastatic. The frequency of the BRCA2 mutation for the different combinations of phenotypes is shown in Table 2.

As the three clinical subgroups (I, II, and III) overlap, we used a Bayesian causal inference in order to estimate the contribution (weight) of each phenotype independently to others. Bayesian analysis is an ideal method for including data in a probabilistic model. It guarantees a consistent probabilistic computation of uncertainty particularly for the prediction of rare events. Using these Bayesian approaches $^{20}$, we found that mutual information $(0.03 \%, 1.7 \%, 0.02 \%$ for phenotype I, II and III, 
respectively) (Figure 1$)$, direct effect $(0.05 \%, 0.1 \%, 0.06 \%$ for phenotype I, II and III, respectively) (Figure 2), and elasticity (4.6\%, 10.9\%, 5.8\% for phenotype I, II and III, respectively), for the mutational positive status were all higher for phenotype II than for the two other ones (Figure 2). So, contribution towards the predicted mean of the positive mutational status, according the direct effect of phenotype observed in each group, was $22 \%, 51 \%$ and $27 \%$ for phenotype I, II and III, respectively. Among the 8 patients who presented both male $\mathrm{BrCa}$ and $\mathrm{PrCa}$, two (25\%) carried a BRCA2 mutation. The frequency of BRCA2 mutation didn't differ according to ethnicity or $\operatorname{PrCa}$ familial status.

The median age at diagnosis of the 21 BRCA2 mutation carriers was 57 years old (Table 3 ). Among them, $42.9 \%$ were diagnosed before 56 years old, and ten (47.6\%) had a relative affected with PrCa: at least one first-degree relative for 7 patients (33.3\%), and at least one second-degree relative for 3 other ones (maternal side, 14.3\%). Fifteen of the BRCA2 mutation carriers (71.4\%) had a personal history of $\mathrm{BrCa}$ or at least one first-degree with $\mathrm{BrCa}$. None of them had a family history of OvCa or UtCa alone. If patients with only a first-degree relative OvCa or UtCa were excluded from Group II, the frequency of BRCA2 mutation in this group increased up to $11.9 \%$. Fifteen $(71.4 \%)$ of the BRCA2 mutation carriers had an aggressive form of the disease (defined as PSA level $>20 \mathrm{ng} / \mathrm{mL}$, or Gleason score $\geq 7$, or T3 stage or presence of local or distant metastases). Four (19\%) of the 21 BRCA2 mutation carriers died from their PrCa after a median follow-up duration of 64.5 months.

\section{DISCUSSION}


The frequency of germline BRCA2 mutation observed in the three studied groups: $5.9 \%$ in Group I, $10.9 \%$ in Group II and $6.9 \%$ in Group III, was always higher than the previously reported one for unselected PrCa populations (ranging from $1.1 \%$ to $2.2 \%) .{ }^{21,22}$ Among the metastatic PrCa patients, the frequency of $B R C A 2$ germline mutation was $6.9 \%$, close to the $5.3 \%$ previously reported. ${ }^{8,9}$ However, the probability of $B R C A 2$ germline mutation without overlap with other subgroups for this group of metastatic patients was $2.7 \%$. In contrast, the mutation frequency of $5.9 \%$ that we observed among PrCa patients diagnosed $\leq 55$ years old was greater than the $2.3 \%$ found by Edwards et al. when they screened 263 PrCa patients diagnosed before 56 years old who were unselected for family history ${ }^{5}$, and the $1.27 \%$ obtained by Kote-Jarai et al. among 632 patients with an age at onset under 56 years old. ${ }^{6}$ The difference in $B R C A 2$ mutation frequency observed between these studies could be explained by the fact that in the last ones, the authors only considered as deleterious the mutations that resulted in a truncated protein. Moreover, the method that they used at this time wasn't able to detect large deletions or rearrangements. The higher frequency observed in our study could also be explained by the presence of around $25 \%$ of patients with a personal or family history of $\mathrm{Br} / \mathrm{Ut} / \mathrm{OvCa}$ in our cohort of young onset patients. However, the proportion of patients with a family history of $\mathrm{Br} / \mathrm{OvCa}$ was quite similar among the patients diagnosed before 56 years old from the study of KoteJarai et al. $(25.3 \%)^{6}$, unlike a lower frequency of $B R C A 2$ mutation. One difference between the two cohorts was the higher frequency of patients with a positive family history of PrCa in our study compared to that of Kote-Jarai et al. (50.7\% versus $34.5 \%)$. In agreement with this observation, we also found a higher frequency of $B R C A 2$ mutation carriers among PrCa patients diagnosed $\leq 55$ years old who had a positive family history of $\operatorname{PrCa}(7.8 \%)$ than those without (4\%), but the difference 
wasn't statistically significant. A larger series of patients should be analysed in order to validate this observation. We also couldn't exclude that this difference in $B R C A 2$ mutation frequency was due to the presence of approximately $20 \%$ of metastatic cases in our cohort of young onset patients, because BRCA2 mutation frequency was only $2.2 \%$ among $\operatorname{PrCa}$ patients who only met the phenotype of a diagnosis before 56 years old.

In our study, the proportion of BRCA2 mutation was significantly higher among the group of patients with a personal history of $\mathrm{BrCa}$ or a first-degree with $\mathrm{Br} / \mathrm{Ut} / \mathrm{OvCa}(\mathrm{P}=0.006)$. This frequency reached $10.9 \%$ and was even slightly higher when we restricted this group to the patients with personal and first-degree relative with $\mathrm{BrCa}$ (11.9\%). This is in accordance with the previously reported observation of a significantly higher frequency of patients with a family history of first- or seconddegree relatives of $\mathrm{BrCa}$ or OvCa among BRCA2 mutation carriers (47.4\%) than non-carriers $(21.3 \%$, $\mathrm{P}=0.024){ }^{6}$ In this study, the authors concluded that in addition to young age of onset of $\operatorname{PrCa}$, the strongest predictors for the presence of a germline $B R C A 2$ mutation was a family history of $\mathrm{BrCa}$ and/or OvCa. ${ }^{6}$ All the families from the BRCA2 mutation carriers of the group II, except one, included one individual that meets at least one criteria of the last version of the NCCN guidelines to perform a BRCA1/BRCA2 testing. ${ }^{23}$ This highlights the importance of evaluating these criteria in families of PrCa patients in order to better select the ones who need this testing. On the contrary, the frequency of BRCA2 carriers wasn't different between patients with and without a positive family history of PrCa. Similarly, Pritchard et al. ${ }^{8}$ reported that the frequencies of germline mutations in DNA-repair genes among patients with metastatic disease did not differ significantly according to family history of PrCa. 
Our study had some limitations. Information on personal and family history of cancer were not derived from medical records, but self-reported by the patient, who may forget or omit some. However, this method of assessment is closer to real life and clinical practice. The cohort of patients isn't large enough to perform stratified analyses, notably by ethnicity or by age. This study isn't population based, patients were selected for BRCA2 screening based on one of the three eligibility criteria and this limits the identification of other clinical criteria that could be associated with the mutations of this gene. Another limitation of this study is that it is restricted to $B R C A 2$ and lacks the inclusion of other DNA-repair genes, as currently, a majority of patients undergoes a multigene panel testing. However, in all reported studies on PrCa patients, BRCA2 is the most frequently mutated gene. Moreover, we can suppose that several patients from our cohort who were tested negative for BRCA2 mutation and had a family history of $\mathrm{BrCa}$ could be carriers of germline mutations in other DNA-repair genes, due to the involvement of these genes in familial BrCa.

In agreement to previous observations, we found that most of the PrCa patients harbouring a germline BRCA2 mutation (71.4\%) had an aggressive form of the disease. Indeed, association between BRCA2 mutation and an advanced PrCa or poor outcomes was consistently observed in previous studies. ${ }^{22,24-27}$ Moreover, genomic analyses of tumours from patients with BRCA2 mutation showed that they harbor increased genomic instability and a mutational profile that more closely resembles metastastic than localized disease.$^{28}$ Similarly, men with familial BrCa were shown to be at greater risk of PrCa, but also of lethal disease. ${ }^{29}$ Even when detected by screening, a high proportion (71\%) of $\mathrm{PrCa}$ at intermediate and high risk was observed among BRCA2 mutation carriers. ${ }^{30}$ 
Altogether, these results suggested that these patients should be early detected and should not be managed with active surveillance, but rather with a more radical treatment.

\section{CONCLUSIONS}

Our results showed that a higher frequency of $B R C A 2$ mutation carriers is observed, not only among PrCa patients with young onset or a metastatic disease, but also with a personal or a familial history of $\mathrm{BrCa}$. It highlights the importance of collecting individual and familial information history $\mathrm{BrCa}$ from PrCa patients in routine clinical practice, notably since $B R C A 2$ mutation is a marker of poor prognosis and has implication for the management of the disease, notably, with the recent development of PARP inhibitors.

\section{ACKNOWLEDGEMENTS}

The authors would like to thank Cécile Gaffory and Valérie Ondet for excellent technical assistance. 


\section{REFERENCES}

1. Macedo GS, Alemar B, Ashton-Prolla P. Reviewing the characteristics of BRCA and PALB2-related cancers in the precision medicine era. Genet Mol Biol 2019, 42, 215-231

2. Kuchenbaecker KB, Hopper JL, Barnes DR, et al. Risks of breast, ovarian, and contralateral breast cancer for BRCA1 and BRCA2 mutation carriers. JAMA 2017, 317, 2402-2416

3. The Breast Cancer Linkage Consortium. Cancer risks in BRCA2 mutation carriers. J Natl Cancer Inst $1999,91,1310-1316$

4. Gayther SA, de Foy KA, Harrington P, et al. The frequency of germ-line mutations in the breast cancer predisposition genes BRCA1 and BRCA2 in familial prostate cancer. The Cancer Research Campaign/British Prostate Group United Kingdom Familial Prostate Cancer Study Collaborators. Cancer Res 2000, 60, 4513-4518

5. Edwards SM, Kote-Jarai Z, Meitz J, et al. Two percent of men with early-onset prostate cancer harbor germline mutations in the BRCA2 gene. Am J Hum Genet 2003, 72, 1-12

6. Kote-Jarai Z, Leongamornlert D, Saunders E, et al. BRCA2 is a moderate penetrance gene contributing to young-onset prostate cancer: implications for genetic testing in prostate cancer patients. Br J Cancer 2011, 105, 1230-1234

7. Leongamornlert D, Saunders E, Dadaev T, et al. Frequent germline deleterious mutations in DNA repair genes in familial prostate cancer cases are associated with advanced disease. Br J Cancer 2014, $110,1663-1672$ 
8. Pritchard CC, Mateo J, Walsh MF, et al. Inherited DNA-Repair Gene Mutations in Men with Metastatic Prostate Cancer. N Engl J Med 2016, 375, 443-453

9. Robinson D, Van Allen EM, Wu YM, et al. Integrative clinical genomics of advanced prostate cancer. Cell 2015, 161, 1215-1228

10. Annala M, Struss WJ, Warner EW, et al. Treatment Outcomes and Tumor Loss of Heterozygosity in Germline DNA Repair-deficient Prostate Cancer. Eur Urol 2017, 72, 34-42

11. Gallagher DJ, Cronin AM, Milowsky MI, et al. Germline BRCA mutation does not prevent response to taxane-based therapy for the treatment of castration-resistant prostate cancer. BJU Int 2012, 109, 713-719

12. Antonarakis ES, Lu C, Luber B, et al. Germline DNA-repair Gene Mutations and Outcomes in Men with Metastatic Castration-resistant Prostate Cancer Receiving First-line Abiraterone and Enzalutamide. Eur Urol 2018, 74, 218-225

13. Castro E, Romero-Laorden N, Del Pozo A, et al. PROREPAIR-B: A Prospective Cohort Study of the Impact of Germline DNA Repair Mutations on the Outcomes of Patients With Metastatic CastrationResistant Prostate Cancer. J Clin Oncol 2019, 37, 490-503

14. Mateo J, Carreira S, Sandhu S, et al. DNA-Repair Defects and Olaparib in Metastatic Prostate Cancer. N Engl J Med 2015, 373, 1697-1708

15. National Comprehensive Cancer Network Clinical Practice Guidelines in Oncology (NCCN Guidelines ${ }^{\circledR}$ ). Prostate Cancer v2.2020.

16. Nicolosi P, Ledet E, Yang S, et al. Prevalence of Germline Variants in Prostate Cancer and Implications for Current Genetic Testing Guidelines. JAMA Oncol. 2019 Apr; 5(4): 523-528. 
17. Giri VN, Knudsen KE, Kelly WK, et al. Role of Genetic Testing for Inherited Prostate Cancer Risk: Philadelphia Prostate Cancer Consensus Conference 2017. J Clin Oncol. 2018 Feb 1; 36(4): 414-424.

18. Thomas G, Jacobs KB, Yeager M, Kraft P, Wacholder S, Orr N, et al. Multiple loci identified in a genome-wide association study of prostate cancer. Nat Genet 2008, 40, 310-315

19. Caputo S, Benboudjema L, Sinilnikova O, Rouleau E, Béroud C, Lidereau R; French BRCA GGC Consortium. Description and analysis of genetic variants in French hereditary breast and ovarian cancer families recorded in the UMD-BRCA1/BRCA2 databases. Nucleic Acids Res 2012, 40(Database issue), D992-1002

20. Conrady S, Jouffe L. Bayesian Networks and BayesiaLab: A practical introduction for Researchers. Bayesia USA: Franklin, USA, 2015.

21. Lang SH, Swift SL, White H, Misso K, Kleijnen J, Quek RGW. A systematic review of the prevalence of DNA damage response gene mutations in prostate cancer. Int J Oncol 2019, 55, 597-616

22. Oh $\mathrm{M}$, Alkhushaym N, Fallatah $\mathrm{S}$, et al. The association of BRCA1 and BRCA2 mutations with prostate cancer risk, frequency, and mortality: A meta-analysis. Prostate 2019, 79, 880-895

23. National Comprehensive Cancer Network Clinical Practice Guidelines in Oncology (NCCN Guidelines ${ }^{\circledR}$ ). Genetic/familial high-risk assessment: Breast and Ovarian v1.2020

24. Carter HB, Helfand B, Mamawala M, et al. Germline Mutations in ATM and BRCA1/2 Are Associated with Grade Reclassification in Men on Active Surveillance for Prostate Cancer. Eur Urol. 2019 May; 75(5): 743-749 
25. Leongamornlert DA, Saunders EJ, Wakerell S, et al. Germline DNA Repair Gene Mutations in Young-onset Prostate Cancer Cases in the UK: Evidence for a More Extensive Genetic Panel. Eur Urol. 2019 Sep; 76(3): 329-337

26. Page EC, Bancroft EK, Brook MN et al. Evidence for prostate specific antigen screening in BRCA2 mutation carriers. Eur Urol. 2019 Dec ;76 (6) :831-42

27. Darst BF, Dadaev T, Saunders E, et al. Germline sequencing DNA repair genes in 5,545 men with aggressive and non-aggressive prostate cancer. J Natl Cancer Inst. 2020 Aug 27:djaa132 (In press).

28. Taylor RA, Fraser M, Livingstone J, et al. Germline BRCA mutations drive prostate cancers with distinct evolutionary trajectories. Nat Commun. 2017, 8:13671

29. Barber L, Gerke T, Markt SC, et al. Family History of Breast or Prostate Cancer and Prostate Cancer Risk. Clin Cancer Res 2018, 24, 5910-5917

30. Bancroft EK, Page EC, Castro E, et al. Targeted prostate cancer screening in BRCA1 and BRCA2 mutation carriers: results from the initial screening round of the IMPACT study. Eur Urol 2014, 66, 489-499. 


\section{Figure Legend:}

Figure 1: Mutual information mapping on the $B R C A 2$ mutation status of the three phenotypes: age at diagnosis at 55 years old and under; personal or family history of breast, uterine or ovarian cancer; or metastatic disease.

Node sizes express for each phenotype the mutual information with the mutational status node.

Figure 2: Direct effect on the BRCA2 mutation status of the three phenotypes: age at diagnosis at 55 years old and under; personal or family history of breast, uterine or ovarian cancer; or metastatic disease.

Horizontal axis indicates values of predicting phenotypes, normalized to scale $0-100$ to make them comparable. Vertical axis indicates means of the outcome variable (mutational status). The analysis was performed by using inference for direct effects. 
Table 1: Characteristics of the 325 patients selected for the study

\begin{tabular}{lc}
\hline & $\mathbf{N}(\%)$ \\
\hline Median age at diagnosis (range) & $57(39-92)$ \\
Age at diagnosis $\leq 55$ years & $152(46.8 \%)$ \\
Family history of PrCa & $128(39.4 \%)$ \\
Personal history of BrCa & $8(2.5 \%)$ \\
Family history of $\mathrm{BrCa}$ & $123(37.8 \%)$ \\
Family history of UtCa or OvCa & $22(6.8 \%)$ \\
Family history of BrCa/UtCa/OvCa & $137(42.2 \%)$ \\
Metastatic PrCa & $130(40 \%)$ \\
Ethnicity & \\
$-\quad$ Caucasian & $270(83.1 \%)$ \\
$-\quad$ African & $45(13.8 \%)$ \\
- & $10(3.1 \%)$ \\
\hline
\end{tabular}

PrCa: prostate cancer; BrCa: breast cancer; UtCa; Uterine Cancer; OvCa: Ovarian cancer. 
Table 2: BRCA2 mutation frequency according the different combination of phenotypes.

\begin{tabular}{|c|c|c|c|c|c|}
\hline $\begin{array}{c}\text { Age at } \\
\text { diagnosis } \leq \mathbf{5 5} \\
\text { years }\end{array}$ & $\begin{array}{c}\text { Personal or } \\
\text { family } \\
\text { history of } \\
\text { Br/Ut/OvCa }\end{array}$ & $\begin{array}{c}\text { Metastatic } \\
\text { PrCa }\end{array}$ & $\begin{array}{c}\text { Number of } \\
\text { patients }\end{array}$ & $\begin{array}{c}\text { Number of } \\
\text { patients } \\
\text { with } \\
\text { BRCA2 } \\
\text { mutation }\end{array}$ & $\begin{array}{c}\text { BRCA2 } \\
\text { mutation } \\
\text { frequency } \\
\text { (\%) }\end{array}$ \\
\hline Yes & No & No & 90 & 2 & $\mathbf{2 . 2}$ \\
\hline No & Yes & No & 76 & 6 & $\mathbf{7 . 9}$ \\
\hline No & No & Yes & 74 & 2 & $\mathbf{2 . 7}$ \\
\hline Yes & Yes & No & 30 & 4 & $\mathbf{1 3 . 3}$ \\
\hline Yes & No & Yes & 24 & 2 & $\mathbf{8 . 3}$ \\
\hline No & Yes & Yes & 24 & 4 & $\mathbf{1 6 . 7}$ \\
\hline Yes & Yes & Yes & 8 & 2 & $\mathbf{1 2 . 5}$ \\
\hline
\end{tabular}

PrCa: prostate cancer; BrCa: breast cancer; UtCa; Uterine Cancer; OvCa: Ovarian cancer. 
Table 3: Characteristics of BRCA2 mutation carrier prostate cancer patients.

\begin{tabular}{|c|c|c|c|c|c|c|c|c|c|c|c|}
\hline Patient & Group & Mutation & $\begin{array}{c}\text { Age at } \\
\text { diagnosis } \\
\text { (Years) }\end{array}$ & $\begin{array}{c}\text { PSA at } \\
\text { diagnosis }\end{array}$ & $\begin{array}{l}\text { Gleason } \\
\text { Score }\end{array}$ & $\begin{array}{l}\text { Tumor } \\
\text { Stage }\end{array}$ & $\begin{array}{c}\text { Local or } \\
\text { distant } \\
\text { Metastases }\end{array}$ & $\begin{array}{c}\text { Alive } \\
\text { (Follow-up } \\
\text { duration) }\end{array}$ & $\begin{array}{l}\text { Relative with } \\
\text { Prostate cancer }\end{array}$ & $\begin{array}{c}\text { Relative with } \\
\text { Breast/Ovarian/uterus } \\
\text { cancer }\end{array}$ & Ethnicity \\
\hline 1 & 1 & c.3264dupT & 48 & 5 & 6 & $\mathrm{~T} 3 \mathrm{~b}$ & NOMO & Yes (185) & $\begin{array}{c}\text { Father, Brother, } \\
\text { Paternal uncle }\end{array}$ & None & Caucasian \\
\hline 2 & $|\&| \mid$ & c.1797_1801del5 & 47 & 11.7 & 6 & $\mathrm{~T} 2 \mathrm{a}$ & NxMO & Yes (4) & Father & $\begin{array}{c}\mathrm{Br}: \text { Sister, Paternal great } \\
\text { grandmother }\end{array}$ & Caucasian \\
\hline 3 & $|\&| \mid$ & c.8297delC & 48 & 38.25 & 8 & $\mathrm{~T} 3 \mathrm{~b}$ & NOMO & Yes (75) & $\begin{array}{l}\text { Maternal uncle } \\
\qquad(\mathrm{x} 2)\end{array}$ & \begin{tabular}{|c|} 
Br: Mother, Sister, \\
Maternal uncle, \\
Maternal Aunt, Maternal \\
cousin x3 \\
Ov/Ut: Maternal \\
grandmother \\
\end{tabular} & Caucasian \\
\hline 4 & 1 & c.6644_6647del4 & 43 & 17 & 6 & $\mathrm{~T} 2 \mathrm{~b}$ & NxMx & Yes (35) & $\begin{array}{c}\text { Father, Paternal } \\
\text { uncle }\end{array}$ & None & Caucasian \\
\hline 5 & II & c.8463dupT & 57 & 500 & M & T3 & NxMx & Yes (37) & Father & $\begin{array}{c}\text { Br: Mother, Paternal } \\
\text { aunt }\end{array}$ & Caucasian \\
\hline 6 & $|\&| \mid$ & c.2808_2811del4 & 52 & 33.75 & 8 & $\mathrm{~T} 2 \mathrm{c}$ & NxMx & Yes (11) & $\begin{array}{c}\text { Father, Paternal } \\
\text { cousin }(x 2)\end{array}$ & Br: Father, Paternal aunt & Caucasian \\
\hline 7 & II & c.1796_1800del5 & 57 & 38 & 8 & $\mathrm{~T} 2 \mathrm{c}$ & N1M0 & Yes (59) & None & $\begin{array}{c}\text { Br: Mother, Sister } \\
\text { Ov/Ut: Sister }\end{array}$ & Caucasian \\
\hline 8 & I \& III & c. $3103 \mathrm{G}>\mathrm{T}$ & 54 & 100 & 9 & T3a & NxM1b & Yes (2) & None & None & Caucasian \\
\hline 9 & II & c.9097dupA & 64 & 5.3 & 6 & $\mathrm{~T} 2 \mathrm{a}$ & NOMO & Yes (80) & None & Br: Mother, Sister (x2) & Caucasian \\
\hline 10 & II & deleterious & 63 & 6 & 7 & $\mathrm{~T} 2$ & NOMO & Yes (NA) & None & Br: Sister & African \\
\hline 11 & II & c. $8167 \mathrm{G}>\mathrm{C}$ & 59 & ND & ND & ND & ND & Yes (NA) & None & Br: Ego & Caucasian \\
\hline 12 & II & c.1310_1313del & 65 & ND & 6 & T1c & NxMx & Yes (NA) & None & $\begin{array}{c}\text { Br: Father, Paternal } \\
\text { uncle }\end{array}$ & Caucasian \\
\hline
\end{tabular}




\begin{tabular}{|c|c|c|c|c|c|c|c|c|c|c|c|}
\hline 13 & $|\&| \mid$ & c. $5909 \mathrm{C}>\mathrm{A}$ & 51 & 0.988 & 6 & $\mathrm{~T} 2 \mathrm{a}$ & $\mathrm{NxMx}$ & Yes (6) & $\begin{array}{l}\text { Paternal } \\
\text { grandfather, } \\
\text { maternal } \\
\text { grandfather }\end{array}$ & $\begin{array}{c}\mathrm{Br}: \text { Mother, sister }(\mathrm{x} 2) \\
\text { Paternal aunt }(\mathrm{x} 2) \\
\text { Maternal aunt }\end{array}$ & Caucasian \\
\hline 14 & $\begin{array}{l}|\&||| \\
\&|| \mid\end{array}$ & c.4168_4169delTT & 52 & 600 & 9 & $\mathrm{~T} 4$ & NxM1b & Yes (3) & Maternal uncle & $\begin{array}{c}\text { BrCa: Mother, Maternal } \\
\text { aunt }\end{array}$ & Caucasian \\
\hline 15 & II \& III & deleterious & 62 & 7 & 7 & T3a & N0M1b & Yes (71) & None & BrCa: Daughter & Caucasian \\
\hline 16 & II \& III & c.1626dupA & 68 & 35 & 9 & $\mathrm{~T} 2 \mathrm{~b}$ & N1M0 & No (56) & None & BrCa: Mother, Sister & Caucasian \\
\hline 17 & III & c.3075_3076delGAinsTT & 68 & 81.54 & 9 & T3a & NxM1b & Yes (2) & None & None & Caucasian \\
\hline 18 & | \& ||| & c. $2283 T>G$ & 55 & 10.63 & 9 & T3a & N1M1a & No (73) & Brother & None & African \\
\hline 19 & II \& III & c.4022del & 74 & 6.65 & 10 & T3 & N1M1c & No (40) & None & $\begin{array}{c}\text { BrCa: Sister } \\
\text { Ov/UtCa: Sister }\end{array}$ & Asian \\
\hline 20 & III & c.1929del & 61 & 2.3 & 8 & $\mathrm{~T} 2 \mathrm{c}$ & N1M1b/M1c & No (85) & Brother & None & Caucasian \\
\hline 21 & II & Del ex1-ex16 & 61 & 5 & 7 & $\mathrm{~T} 2 \mathrm{C}$ & NxMx & Yes (42) & None & $\begin{array}{c}\text { BrCa: Ego, Sister (x3), } \\
\text { Paternal aunt }(x 3)\end{array}$ & Other \\
\hline
\end{tabular}

BrCa: breast cancer; Ov/UtCa; Ovarian or Uterine Cancer; M: moderately differentiated; NA : not available. 
Figure 1

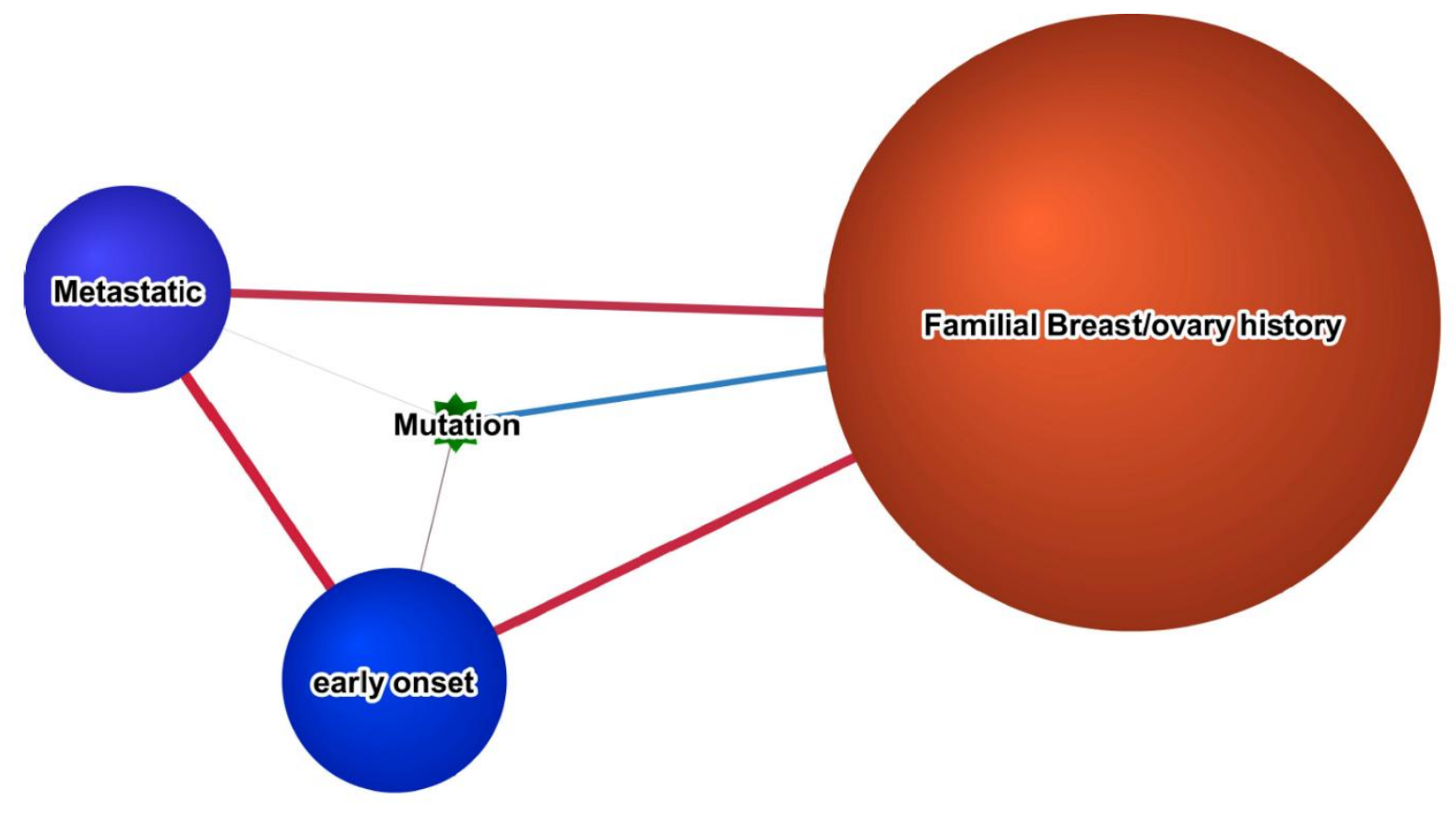


Figure 2

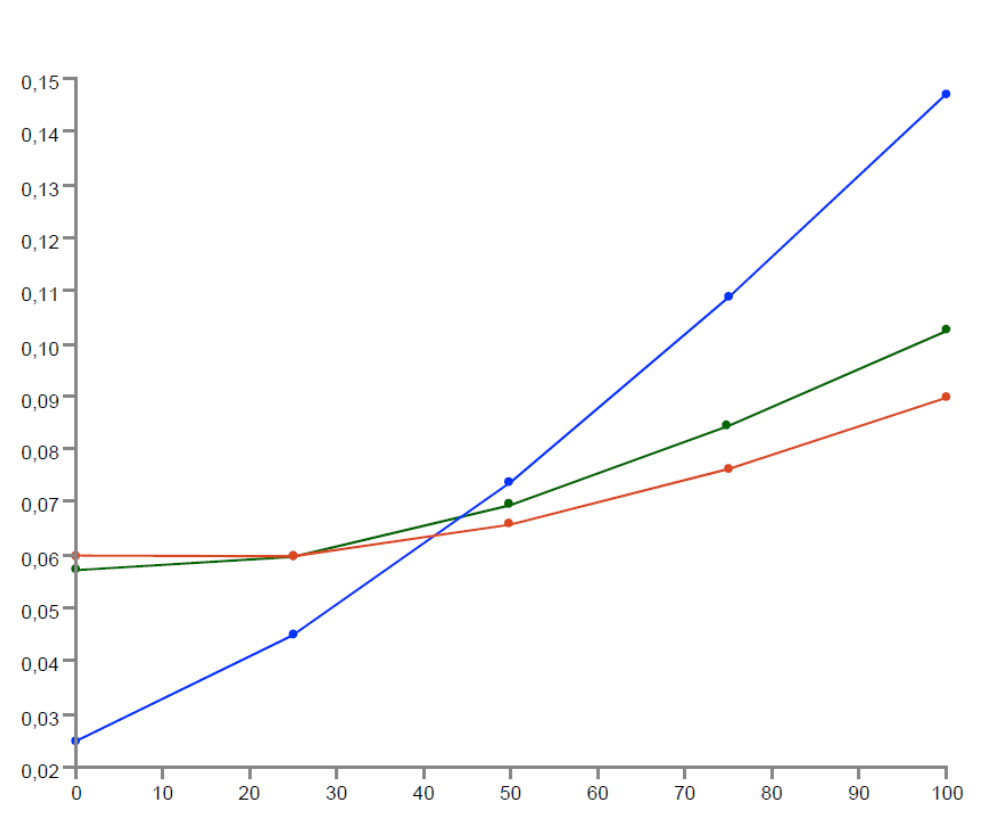

Metastatic

Г Familial Breast/ovary history

厂 early onset 